\title{
Dentists urged to reduce their carbon footprint
}

$\mathrm{V}$

arious steps can be taken by dentists to try to reduce the carbon footprint of their work, according to Public Health England (PHE).

PHE published a report ${ }^{1}$ on 13 July 2018 in which it examined the environmental impact of dental work and ways in which it could be reduced in line with national efforts to cut the carbon footprint of the NHS and the UK.

The report, written for PHE by the Centre for Sustainable Healthcare, stresses how important it is to improve sustainability and reduce carbon emissions and cites the UK and NHS targets to reduce carbon emissions by $34 \%$ by 2020 and more than $80 \%$ by 2050 .

The NHS had expanded its efforts from a focus on direct use of natural resources such as water, energy, fuel and waste to looking at the opportunities to reduce the social and environmental impacts from procurement and clinical pathways.

For the report, the authors said they wanted to calculate and analyse the carbon footprint of 17 of the most common dental procedures, including both high volume and resource intensive treatments, and to identify types of service which were responsible for large amounts of greenhouse gas emissions.

Therefore, they calculated the carbon emissions of NHS dental services in England associated with patient travel, staff commuting, business travel, procurement, gas and electricity use, waste disposal, water use and nitrous oxide release.

Once the total greenhouse gas emissions were estimated, emissions were allocated by the different procedures by standard denominators, such as time spent on procedure, number of visits per procedure or claim value of procedure.

This provided a way to identify the types of dental procedures responsible for large amounts of greenhouse gas emissions.

The report says that in 2013 to 2014, the total greenhouse gas emissions of NHS dental services in England measured in tonnes of carbon dioxide equivalents (tCO2e) was 675,706 - this was equivalent to flying 50,000 times from the UK to Hong Kong and made up 3\% of the overall carbon

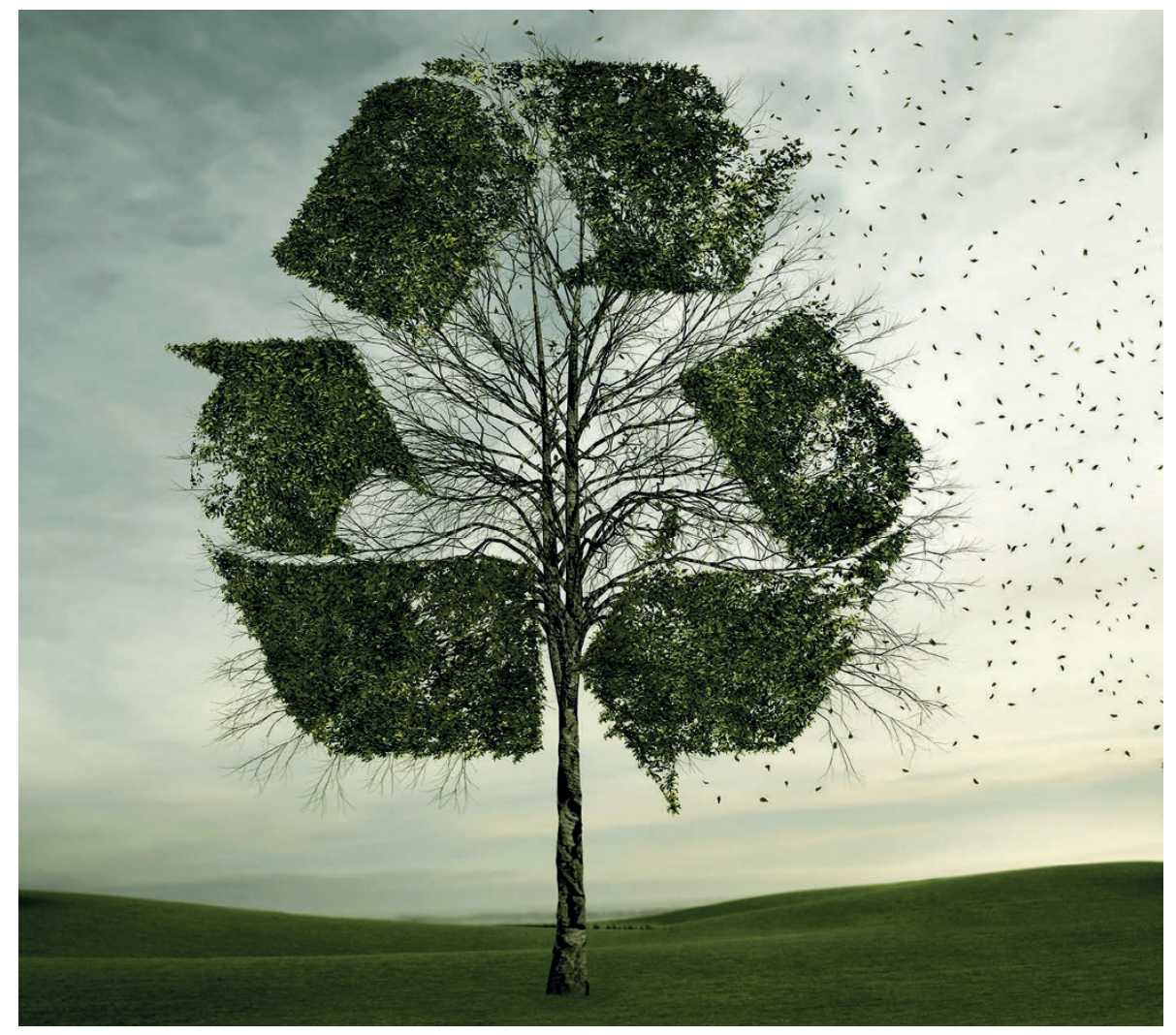

footprint of the NHS in England.

The analysis showed that travel - by both patients and staff - was the main source of carbon emissions by NHS dental services as a whole and for the majority of dental procedures. For ten of the analysed procedures, travel made up more than $60 \%$ of the dental carbon footprint.

Therefore the authors recommend reviewing service configuration to try to reduce the amount of travelling by patients and staff. This could be achieved in various ways such as dentists planning treatment to reduce the number of visits needed and further implementation of NICE guidance on the interval between courses of treatment might also help, whilst still being considerate of patient choice.

To be able to tackle dental procurement - the second highest contributor to the greenhouse gas emissions - detailed research into the carbon emissions of dental products was required, said the authors.

The collection and improvement of dental carbon footprinting data and the linking of carbon data to cost-benefit analysis of treatments would help with the identification of effective, patient-centred treatment with reduced environmental impact, they argued.

'Dental services can become more sustainable on the ground by improving the sustainability of travel, procurement and the management of their dental practices', says the report.

When looking at the carbon footprint of the 17 procedures, the dental examination contributed the highest proportion (27.1\%) to the overall carbon footprint, and others included:

- Scale and polish (13.4\%)

- Amalgam and composite fillings (9.7\% and $9.5 \%$ respectively)

- Acrylic dentures (8.6\%)

- Radiographs (6.4\%)

- Extractions (3.5\%)

- Nonprecious metal crowns (3.3\%)

- Fluoride varnish (2.9\%)

- Endodontic treatment (2.1\%)

- Precious metal crowns, metal dentures, fissure sealants and porcelain crowns contribute less than $1 \%$ to the carbon dioxide equivalents of dental procedures. 
4 In the report's foreword, Sandra White, National Lead for Dental Public Health, and Sara Hurley, Chief Dental Officer for England, said: 'For patients, we must re-enforce our messages to encourage prevention of dental disease using Delivering Better Oral Health guidance. ${ }^{2}$ Improved oral health will not only reduce dental treatments, but also the frequency of recall visits in line with the NICE recall guidance.

'The report alerts dental teams to take immediate and sustained action to reduce travel. Dental practices can adopt, encourage and facilitate active travel such as cycling and walking, to and from work where possible. This in turn will not only reduce the carbon footprint of the business, but also improve cardiovascular, general health and wellbeing of the team.'

Ingeborg Steinbach, Project Manager at the Centre for Sustainable Healthcare and author of the report, said: 'With NHS primary dental being provided by over 20,000 dentists in over 8,000 dental practices it is important that everyone does their share.

'It is important to acknowledge that staff travel contributes a nearly equal amount to the NHS dental carbon footprint as patient travel.

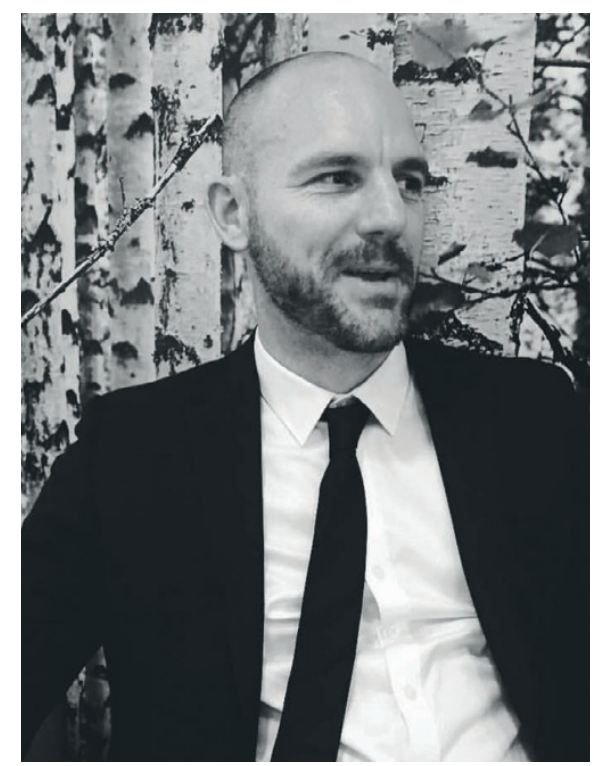

Dr Brett Duane, Associate Professor in Dental Public Health at Dublin Dental University Hospital

Dental staff can start by reviewing their own travel behaviour. Are they able to consider active travel for their commute? Would it be possible to opt for public transport or are there opportunities for lift sharing?'

One of the report co-authors Dr Brett Duane, Associate Professor in Dental Public Health at Dublin Dental University Hospital, said: 'There is a lot that dentists can do to reduce the carbon footprint, and in doing so help their practice become both more environmentally and financially sustainable.

'This can be as simple as changing to energy efficient LED lightbulbs, to printing double-sided, and incorporating recycling into the dental surgery.

On the issue of travel, Duane added: 'There are a number of ways the impact of travel can be reduced. Reducing the number of appointments is key here; so seeing family members together, combining for example a scale and polish and examination - all these reduce the number of travel visits.

'The dental practice can also encourage active travel; install safe secure cycle facilities, and encourage patients to link their appointments with public transport.'

1. Public Health England and Centre for Sustainable Healthcare. Carbon modelling within dentistry: Towards a sustainable future (July 2018). https://assets. publishing.service.gov.uk/government/uploads/system/ uploads/attachment_data/file/724777/Carbon_modelling_within_dentistry.pdf (accessed 16 July 2018).

2. Public Health England, Department of Health. Delivering Better Oral Health (March 2017). https://www.gov.uk/ government/publications/delivering-better-oral-healthan-evidence-based-toolkit-for-prevention (accessed 16 July 2018).

\section{Large cereal manufacturer cuts sugar content by $40 \%$}

The amount of sugar in large cereal manufacturer Kellogg's well-known brand Coco Pops has been cut by $40 \%$ from $30 \mathrm{~g}$ per $100 \mathrm{~g}$ to $17 \mathrm{~g}$ per $100 \mathrm{~g}$.

Kellogg's said that it had been working on the formulation for Coco Pops - one of the best-selling cereals in the UK - for more than three years to cut its sugar content.

The new recipe, which has gone on sale from late July 2018, now includes a more premium cocoa powder and no artificial preservatives or sweeteners, according to the company.

The latest sugar reduction follows a reduction of $14 \%$ last year, meaning that from 2017 to 2018, Kellogg's have halved the sugar in Coco Pops, which also now has $10 \%$ less salt.

The company said it had tested the new recipe with 117 children and 117 parents and almost $85 \%$ of the children said they liked the lower sugar recipe just as much as the previous one.
Bridget Briggs, head of Research and Development for cereal at Kellogg's: 'Kellogg's has a long tradition of helping improve the nation's diet - from pioneering high fibre foods in the early 1900s to adding vitamin $\mathrm{D}$ to all our kid's cereals in 2000s.

'We know people want to eat healthier in the morning and they are asking us for help, so we are acting. That's why we have worked hard over the last three and a half years to reduce the amount of sugar in Kellogg's Coco Pops. This started with a $14 \%$ reduction last year. We have now reduced by another $40 \%$ meaning that from 2017 to 2018, Kellogg's will have halved the sugar in Coco Pops.

'People have told us that taste is still important to them so my team of food developers have worked hard to ensure that our new recipe is just as delicious. We will continue to listen to people about how we can improve our food.'

Kawther Hashem, nutritionist at cam-

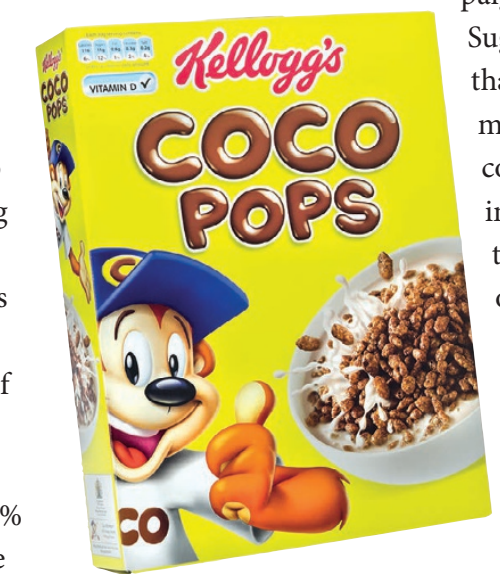
paigning group Action on Sugar said: 'It's no secret that confectionery and many cereals are a major contributor to sugar intake which is linked to the development of obesity and is rotting our children's teeth. 'It should be mandatory for all confectionery products to be reformulated - not just on sugar content, but on overall energy-density of products (removal of both fat and sugar). For those manufacturers who don't comply, a levy of $20 \%$ (minimum) should be added to all their sweet and chocolate confectionery'. 